\title{
In some Languages, /s/ is a Vowel"
}

\author{
Heather Goad and Akiko Shimada \\ McGill University
}

\section{Introduction}

It has long been known that, in clusters, /s/ fails to respect the phonotactic constraints that hold of other obstruents. For example, while branching onsets must rise in sonority in the vast majority of languages, no such requirement holds of $/ \mathrm{s} /$-initial clusters. In fact, the optimal $\mathrm{sC}$ cluster across languages is $/ \mathrm{s} /+\mathrm{stop}$ in shape (Goad 2011). Although this would appear to be perceptual suicide for a regular obstruent, what makes /s/ different is that it has robust cues for place and manner, which ensures its perceptibility regardless of what it is adjacent to (Wright 2004, Toda, Maeda \& Honda 2010). Unlike other obstruents, then, /s/ does not need to 'lean on' an adjacent sonorant to be heard. Although the perceptual properties of /s/ enable it to occur relatively freely, this observation only goes part way toward explaining its unusual distribution (Goad 2011, 2012). Indeed, in research that adopts an articulated view of the syllable, the unusual behaviour of $/ \mathrm{s} /$ has been captured by assigning it some special status: treating it as an appendix in sC/Cs clusters (see Vaux \& Wolfe 2009); as a coda preceded by an empty nucleus in (initial) sC clusters (following Kaye 1992); or as part of a complex segment in /s/+stop clusters (e.g. van de Weijer 1996).

None of these proposals contests the position that $/ \mathrm{s} /$ is an obstruent. In contrast, we defend the view that /s/ can be a vowel -a strident vowel- in some languages precisely because, like a vowel, it has strong internal cues to ensure its perceptibility. This position predicts the existence of a language where /s/ goes well beyond the appendix-like behaviour it exhibits in other languages. We demonstrate that Blackfoot, an Algonquian language spoken in southern Alberta and northwestern Montana, is such a language.

The extent of the unusual behaviour that /s/ displays in Blackfoot can be briefly exemplified as follows. In addition to the cross-linguistically common pattern where word-initial [s] can be followed by a

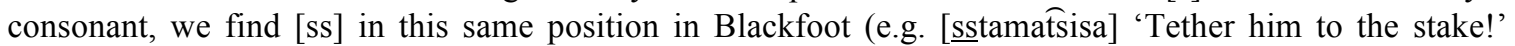
(D229). ${ }^{1}$ In medial position, both [s] and [ss] can be sandwiched between consonants (e.g. [áakokstakiwa] 'She will count' (G79), [itápsskonakiwaiksi] '(My friend) shot at them' (G50)); and medial [sss], as well as [ss], can be preceded or followed by a consonant if a flanking vowel appears at the other edge (e.g. [stámsssáakonoosa] 'Try to recognize her!' (D166); [ínikáto?katsiiwa anníisska óssska] 'he imitated his son-in-law’ (D61)).

As will be shown in the analysis to follow, these unusual examples can be accounted for if, comparable to other vowels in Blackfoot, /s/ is underlyingly monomoraic (like /i/) or bimoraic (like /i:/), in addition to being non-moraic (like /y/). Depending on its position in the string, moraic/s/ will surface as a syllable head and/or coda, sometimes with links to preceding or following onsets as well. None of this, we argue, has to be stipulated: the segmental context in which /s/ occurs determines its realization. Our analysis builds on earlier work on Blackfoot: Derrick (2006) states that Blackfoot /s/ "sometimes acts like a vowel" and Denzer-King (2009:51) proposes that “/s/ is inherently moraic, and can act as a syllable nucleus". However, it differs from both of these earlier works in clear and substantive ways, some of which will be discussed in this paper (see further Goad \& Shimada 2014).

\footnotetext{
* Parts of this paper were presented at mfm 2012, NELS 2013, CLA 2013, MOT 2013, Memorial University of Newfoundland and McGill University, as well as at Phonology 2013. We would like to thank the audiences for questions and comments. This research was supported by grants from SSHRC and FRQSC.

${ }^{1}$ All data in this paper come from Frantz's (2009) grammar (henceforth G) and Frantz \& Russell's (1995) dictionary (D), unless otherwise noted. Numbers following $G$ and D refer to page numbers in these sources.
}

(C) 2014 Heather Goad and Akiko Shimada

Proceedings of Phonology 2013

Completed February 15, 2014 


\section{Consonants in Blackfoot}

We take the position that a principled analysis of /s/ first requires examination of the distribution and syllabification of other consonants in Blackfoot. We thus begin by considering the distribution of consonants in this language. See (1).

Consonant inventory:
\begin{tabular}{|l|c|c|c|c|}
\hline & Labial & Coronal & Dorsal & Placeless \\
\hline Stop & $\mathrm{p}$ & $\mathrm{t}$ & $\mathrm{k}$ & $?$ \\
\hline Complex stop & & $\widehat{\mathrm{ts}}$ & $\widehat{\mathrm{ks}}$ & \\
\hline Fricative & & $\mathrm{s}$ & & $\mathrm{h}$ \\
\hline Nasal & $\mathrm{m}$ & $\mathrm{n}$ & & \\
\hline Glide & $\mathrm{w}$ & $\mathrm{y}$ & & \\
\hline
\end{tabular}

The symbols in (1) correspond to those used by Frantz (2009) with the following exceptions: / $/$ / replaces /'/ and $/ \mathrm{ts}, \widehat{\mathrm{ks}} /$ replace some instances of $/ \mathrm{ts}, \mathrm{ks} /$. We opt for the ligature for the latter consonants because the alternative transcriptions, /ts/ and /ks/, are ambiguous in Blackfoot (Frantz 2009): lingual stop + fricative can form clusters or complex segments. In some contexts, the analysis is indeterminate; in most others, we argue that distributional considerations are revealing of the appropriate structure (Goad \& Shimada 2014).

The most striking property of the inventory in (1) is that Blackfoot lacks liquids. It also does not have a laryngeal contrast amongst obstruents. We have labelled the final column as placeless, which we motivate on distributional grounds below.

Data and generalizations in Frantz \& Russell (1995), Elfner (2006a), Denzer-King (2009) and Frantz (2009) lead us to divide the consonants from (1) into four classes, as shown in (2). Note that the distribution of unusual $/ \mathrm{s} /$ is not under present consideration.

Distribution of consonants:
\begin{tabular}{|l|c|c|c|c|}
\hline & Labial & Lingual (not /s/) & Ordinary/s/ & Placeless \\
\hline Word-initial onset & $\checkmark$ & $\checkmark$ & $\checkmark$ & $x$ \\
\hline Intervocalic onset & $\checkmark$ & $\checkmark$ & $\checkmark$ & $x$ \\
\hline $\begin{array}{l}\text { Word-internal coda } \\
\text { (geminates aside) }\end{array}$ & $x$ & $x$ & $\checkmark$ & $\checkmark$ \\
\hline Word-final consonant & $?$ & $\begin{array}{c}\checkmark \\
\text { (except complex stop) }\end{array}$ & $\checkmark$ & $x$ \\
\hline
\end{tabular}

Leaving aside ordinary $/ \mathrm{s} /$ for the moment, a glance at the table reveals that labials and linguals, on one hand, and placeless consonants, on the other, principally occur in complementary contexts: the former two are restricted to onset position and placeless consonants, to coda. The division of labials and linguals into two classes is based on their distribution in word-final position: although stems can end in labials, it appears that these consonants cannot occur word-finally, with limited exceptions; this contrasts with noncomplex lingual contoids, which can appear in this position, along with ordinary /s/. Our understanding of the constraints that hold of word-final consonants, however, is limited at present and we will thus exclude them from further discussion.

Turning now to $/ \mathrm{h} /$, we propose that this fricative, along with $/ \mathrm{R} /$, is inherently placeless. Note, though, that $/ \mathrm{h} /$ is always realized with a tongue body gesture - it surfaces as [c] after $/ \mathrm{i} /$, as $[\mathrm{x}]$ after $/ \mathrm{a} /$, and as $\left[\mathrm{x}^{\mathrm{w}}\right]$ after /o/ (Frantz 2009) - leading some researchers to phonemicize it as /x/ (e.g. Frantz 2009:162, Elfner 2006a:12). Our arguments for $/ \mathrm{h} /$ as placeless are as follows. First, if $/ \mathrm{h} /$ were underlyingly place-bearing (i.e. $/ \mathrm{x} /$ ), we would expect it to pattern with the linguals and yet (2) reveals that it does not. Second, its restriction to coda position is consistent with the cross-linguistic observation that codas cannot license their own place features (e.g., Itô 1986); conversely, its absence from onset position follows if onsets must bear place features in some languages ( $\mathrm{Qu}$ 2011). Finally, $/ \mathrm{h} /$ has the same distribution as $/ \mathrm{P} /{ }^{2}$ a segment which

${ }^{2}$ There are a handful of examples of intervocalic glottal stop, which we treat as exceptions. 
is standardly considered to lack place (e.g. Steriade 1987, Rose 1996). The observation that placeless /h/ assumes the vocal tract shape of adjacent vowels in Blackfoot holds of $/ \mathrm{h} /$ in many other languages as well (see e.g. Keating 1988 on English, Farsi and Swedish).

Turning finally to ordinary $/ \mathrm{s} /$, this consonant has a freer distribution than other consonants in Blackfoot. This, however, does not question its status as ordinary. The freer distribution emerges from the fact that it is both a fricative and coronal, as will be discussed further below.

The complementary distribution of labials/linguals and placeless consonants observed in (2) will be essential for our analysis of unusual/s/ which, as we have seen, can be both preceded and followed by consonants. When preceded by [p], for example, a consonant that can only be in onset, we can conclude that the immediately following [s] is nuclear (e.g. [itápsskonakiwaiksi] '(My friend) shot at them' (G50)); when preceded by a placeless consonant, by contrast, the immediately following [s] must be in onset (e.g.

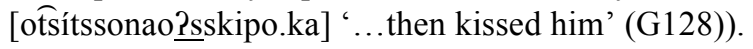

\section{Syllabification}

The distribution of consonants in (2) hints at the observation that, when unusual /s/ is set aside, Blackfoot syllabification is relatively straightforward. We discuss this more concretely in this section, beginning with onsets. First, true branching onsets are banned in Blackfoot. This is not surprising, as we observed in (1) that the language lacks liquids. Obstruent + liquid is the most commonly attested profile for branching onsets; indeed some researchers have argued that other clusters cannot have this analysis in the absence of obstruent + liquid (Clements 1990), a position that we accept. In view of this, our approach precludes a complex onset analysis of $\mathrm{sC}$ and Cs clusters, in contrast to the analysis proposed by Elfner $(2006 a, b)$. The constraint in (3) is thus undominated in our analysis.

\section{NOCOMPLEXONSET: Complex onsets are forbidden}

Second, word-medial syllables generally require onsets. According to Elfner (2006a), vowels in hiatus are resolved through coalescence $(/ \mathrm{a} /+/ \mathrm{i} / \rightarrow[\varepsilon:], / \mathrm{a} /+/ \mathrm{o} / \rightarrow[0:])$, diphthong formation $(/ \mathrm{i} /+/ \mathrm{a} / \rightarrow$ [ya $]$, $/ \mathrm{i} /+/ \mathrm{o} / \rightarrow[\mathrm{yo}], / \mathrm{o} /+/ \mathrm{i} / \rightarrow[\mathrm{oy}])$ and, rarely, elision $(/ \mathrm{i} /+/ \mathrm{a} / \rightarrow[\mathrm{a}], / \mathrm{i} /+/ \mathrm{o} / \rightarrow[\mathrm{o}], / \mathrm{o} /+/ \mathrm{a} / \rightarrow[\mathrm{a}])$. Hiatus is tolerated only with $/ \mathrm{o} /+/ \mathrm{a} /(\rightarrow[\mathrm{o} . \mathrm{a}])$. The prohibition against vowels in hiatus is due to high-ranking NoHiatus, which we define in (4). As Elfner (2006a) and Denzer-King (2009) point out, the patterns exhibited cannot instead be attributed to ONSET, the constraint forbidding onsetless syllables: vowel-initial words are perfectly licit in Blackfoot ([akóka?tssiistsi] 'circle camps' (D10)); in fact, initial glides are often deleted (/w-óko?s-iksi .../ $\rightarrow$ [óko?siksi ...] 'His kids (are sleeping)' (G49)). Indeed, the low importance of ONSET will be a critical part of our analysis of word-initial $\mathrm{sC}$ and $\mathrm{ssC}$ clusters (see $\S 6$ ).

NoHiatus: Adjacent segments linked to separate $\mu$ nodes cannot be in different syllables

In addition to repairing adjacent VV strings (aside from /o/ + /a/), high-ranking NoHIATUS will have the following effect in our analysis: it will force onset formation in the case of medial consonants which will, in some circumstances, yield the patterns that have thus far been described as involving unusual $/ \mathrm{s} /$.

Turning to codas, Blackfoot syllables follow the cross-linguistically common pattern where (wordmedial) codas cannot license place features. Accordingly, aside from ordinary /s/, codas are limited to the first half of geminates, as shown in (5a), ${ }^{3}$ and to placeless consonants, shown in (5b-c).

Place in codas:
a. [nínna] /miin-ohkot-k-i-t/ $\rightarrow$ [miinohkókkit]
'my father' (G5)
b. [áakohpotaawa]
'Don't give it to me!' (G83)
[sstsipísoohsit]
'It's going to snow' (G24)
c. [mo?tsíí]
'Punish (whip) yourself!' (G105)
'hand/arm' (G12)
[ma?tóós]
'Take it! (anim, sing addressee) (G112)

\footnotetext{
${ }^{3}$ Placeless consonants (Frantz 2009) and glides (Denzer-King 2009) cannot geminate in Blackfoot.
} 
Considering now ordinary $/ \mathrm{s} /$, it patterns as expected. It can geminate like other consonants, as shown in (6a), and aside from a handful of exceptions, it respects constraints on place licensing: it must be followed by coronals, $(6 b)$.

(6) Place in codas: Ordinary $/ \mathrm{s} /$ :
a. [ikśrssiwa] 'he is tough' (G5)
b. [nitánistawa] 'I told him' (G154)
[mínistsi] 'berries' (G94)

In addition, as observed earlier, placeless consonants are confined to coda position. Their absence from onset position is consistent with what is observed in some other languages, where onsets must bear place features (Qu 2011; see also Harris 1997). The relevant place constraints, both undominated, ${ }^{4}$ are in (7).

$$
\begin{aligned}
& \text { NOCODAPlace: Coda cannot license place } \\
& \text { OnSETPLACE: Onset consonants have place }
\end{aligned}
$$

Finally, Blackfoot respects the Syllable Contact Law (Murray \& Vennemann 1983): codas can be followed by segments of equal or lower sonority. In Blackfoot, this effectively reduces to fricative + (complex) stop or fricative, as shown for $/ \mathrm{h} /$ in $(8 \mathrm{a})$ and for ordinary $/ \mathrm{s} /$ in $(8 \mathrm{~b}){ }^{5,6}$ The relevant constraint is defined in (9).

(8) Syllable contact: Fricatives:
a. $/ \mathrm{h} /+($ complex $)$ stop:
/h/+fricative:
[aisstaahkahtaawa]
[sstsipísoohsit]
'She is nursing' (G103)
[áaksikáóka?pihtsiiyiwa] '...it will have spoiled' (G36)
'Punish (whip) yourself!' (G105)
$\begin{array}{ll}\text { b. } / \mathrm{s} /+(\text { complex }) \text { stop: } & {[\text { nitánistawa] }} \\ & {[\text { míniststsi] }}\end{array}$
'I told him' (G154)
'berries' (G94)

(9) SyllableContact: An onset consonant cannot be more sonorous than the immediately preceding coda

Note that [?], in contrast to [h], can be followed by any consonant, (10), seemingly in violation of SYLLABLECONTACT. We assume that [?] is featureless and so escapes syllable contact constraints. [h], by contrast, is placeless, like [?], but specified for [cont], like [s].

\begin{tabular}{|c|c|c|}
\hline /P/+(complex) stop: & $\begin{array}{l}\text { [ni?tómmoyi] } \\
\text { [i?kssisakovi] }\end{array}$ & $\begin{array}{l}\text { 'hill' (G7) } \\
\text { 'meat' (G7) }\end{array}$ \\
\hline$/ 2 /+$ fricative: & [asóka?simi] & 'dress' (noun) (G11) \\
\hline /P/+nasal: & [i?nákohkitsimi] & 'small doorway' (G78) \\
\hline /?/+glide: & [áwa?yiwa] & 'She is pointing' (G27) \\
\hline
\end{tabular}

(10) Syllable contact: Glottal stop:

\section{Unusual /s/}

From the preceding section, we can conclude that Blackfoot syllable structure is relatively straightforward: constraints on the distribution of consonants are governed by considerations of both

\footnotetext{
${ }^{4}$ But see note 2 on glottal stop.

$5 / \mathrm{s} / \mathrm{+} / \mathrm{h} /$ is not observed due to ONSETPlace.

${ }^{6}$ Blackfoot does not permit sonorants in coda, including nasals that share place with following onsets. Although this can be attributed to an undominated constraint against sonorant codas, we leave this aside, as it will not prove to be relevant for the data under discussion.
} 
sonority and place, similar to what is observed in other languages. ${ }^{7}$ We can further conclude that the seemingly freer distribution of ordinary /s/ in (2), when compared with other consonants, arises not from anything special about ordinary /s/ but, rather, from the fact that it is both coronal and a fricative.

We turn now to consider more carefully the contexts where unusual $/ \mathrm{s} /$ is observed. As will be imminently evident, examples with unusual /s/ appear to flagrantly violate the constraints introduced in the preceding section.

We begin with medial position. The examples in (11) show that medial [s] and [ss] can be flanked be consonants. The examples in (12) reveal that [ss] and [sss] can be preceded by a consonant if followed by a vowel, and those in (13), that [ss] and [sss] can be followed by a consonant if preceded by a vowel. (These contexts will be added to in $\S 5$ below.)

$$
\begin{aligned}
& \text { Medial [s] and [ss] in context C_C: } \\
& \begin{array}{lll}
\text { a. } \quad \text { [áakokstakiwa] } & \text { b. } & \text { [itápsskonakiwaiksi }] \\
\text { 'She will count' (G79) } & \text { '(My friend) shot at them' (G50) }
\end{array}
\end{aligned}
$$

Medial [ss] and [sss] in context C__ V:
a. [kitssoká?pssi]
'You are nice' (G23)
b. [ááhsssapiwa]
'He enjoyed watching' (D258)
Medial [ss] and [sss] in context $\mathrm{V} \_\mathrm{C}$ :
a. [ísska] 'pail' (G14)
b. [ínikáto?katsiiwa anníisska óssska]
'he imitated his son-in-law' (D61)

Turning to initial position, the $\mathrm{sC}$ data in (14a) are not particularly surprising, in view of what is observed in other languages (D-K data are from Denzer-King 2009). Those in (14c), however, show that, in addition to initial sC, Blackfoot permits ssC. Observe that both [s] and [ss] in (14a) and (14c) can be followed by the same range of consonants -(complex) stops at any place of articulation-indicating that the same type of analysis should hold for both contexts. By contrast, initial sC differs from medial sC in (14b), suggesting that a different analysis should hold for these two contexts: the latter respects place identity.

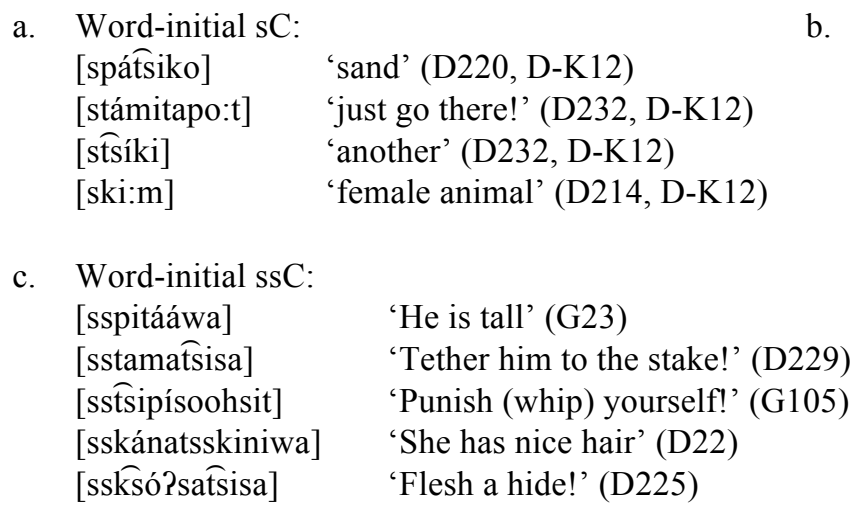

a. Word-initial sC: [spátsiko] 'sand' (D220, D-K12) [stámitapo:t] 'just go there!' (D232, D-K12) [stsíki] 'another' (D232, D-K12) [ski:m] 'female animal' (D214, D-K12)

c. Word-initial ssC:

$\begin{array}{ll}\text { [sspitááwa] } & \text { 'He is tall' (G23) } \\ \text { [sstamatsisa] } & \text { 'Tether him to the stake!' (D229) } \\ \text { [sstsipísoohsit] } & \text { 'Punish (whip) yourself!' (G105) } \\ \text { [sskánatsskiniwa] } & \text { 'She has nice hair' (D22) } \\ \text { [ssksó?satsisa] } & \text { 'Flesh a hide!' (D225) }\end{array}$
b. Compare word-medial sC (6b): $*[\mathrm{VspV}]$ [nitánistawa] 'I told him' (G154) [mínistsi] 'berries' (G94) $*[\mathrm{VskV}]$

Forms with unusual /s/ seem not to abide by the syllabification constraints introduced in $\$ 3$. Contrary to appearance, we will show in $\S 5$ that analysing /s/ as a vocoid leads to a straightforward analysis of these complex patterns, one that is consistent with the syllable structure constraints introduced earlier.

\footnotetext{
${ }^{7}$ Elfner (2005) and Denzer-King (2009) consider sonority to be the driving factor in Blackfoot syllabification. Place constraints, which we believe are essential to an understanding of the distribution of $/ \mathrm{s} /$ and other consonants, do not play a crucial role in their analyses.
} 


\section{Analysis}

Our goals are as follows: (i) to analyse unusual /s/ using the same inventory of syllable constituents available to ordinary segments, that is, without recourse to appendices (cf. Denzer-King 2009) or nonexhaustive syllabification; and (ii) to clearly identify the conditions under which unusual /s/ is permitted without relaxing the syllable contact constraints holding for other consonants (cf. Elfner 2006a,b).

To achieve these goals, we propose the following. We adopt moraic theory (Hyman 1985, Hayes 1989), as it is the only theory of syllabification that provides the flexibility required for the various parses of $/ \mathrm{s} /$. We propose that ordinary $/ \mathrm{s} /$ and unusual $/ \mathrm{s} /$ are distinguished in terms of moraicity and syllabification. Similar to other consonants, ordinary /s/ is underlyingly non-moraic or monomoraic. Nonmoraic /s/ is syllabified as an onset, or acquires weight-by-position (WBP) (Hayes 1989) when syllabified in coda. Underlyingly monomoraic $/ \mathrm{s} /$, when intervocalic, yields a geminate.

Unusual /s/ can also be underlyingly monomoraic, or bimoraic, but it differs from intervocalic [ss] in that it projects its own syllable. ${ }^{8}$ This, however, does not need to be stipulated: the segmental context in which /s/ occurs determines its syllabification. In short, then, ordinary and unusual /s/ are not formally different, aside from their underlying moraic structure. Their differences arise from the contexts in which they occur. We will nevertheless continue to use the terms ordinary /s/ and unusual /s/ for ease of reference.

5.1 Ordinary $/ s /$ In the interest of completeness, we begin with ordinary /s/. In intervocalic position, non-moraic /s/ undergoes onset adjunction, in order to satisfy NoHiATUS, as shown in (15a). In coda position, /s/ acquires a mora to satisfy WPB, (15b).

Underlyingly non-moraic $/ \mathrm{s} /$ :

a. Onset: [póó.sa] 'cat' (G9)

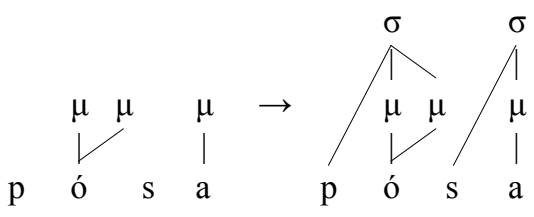

b. Coda: [míínis. Tsi] (6b)

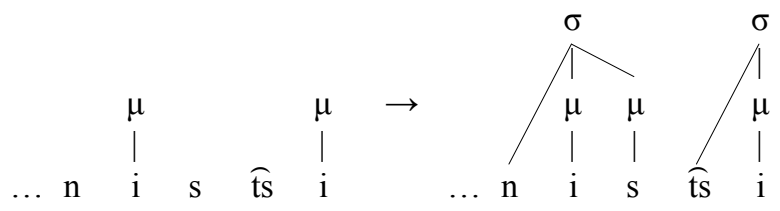

Monomoraic/s/ in intervocalic position surfaces as a geminate; see (16). NoHiATUS is responsible for onset adjunction, indicating that this constraint is effectively equivalent to ONSET operating word-internally.

Underlyingly monomoraic /s/:

[i.ksís.si.wa] (6a)

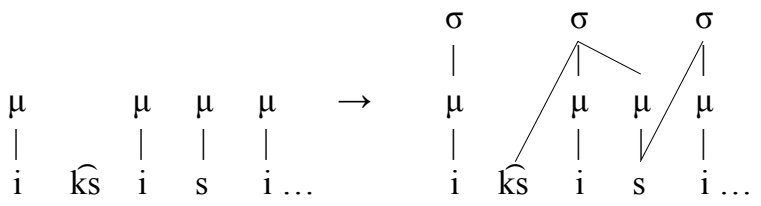

5.2 Monomoraic unusual /s/ Monomoraic unusual/s/ yields Cs syllables, as can be seen in (17). In column (i), the Cs syllable is preceded by a vowel and in column (ii), by a consonant. $/ \mathrm{s}_{\mu} /$ is syllabified as

\footnotetext{
${ }^{8}$ As mentioned earlier, our analysis builds on Denzer-King (2009), who also proposes that /s/ is underlyingly monomoraic or bimoraic and can project a syllable. Denzer-King, however, assumes that /s/ is moraic in all positions (p. 52). He thus has no principled way to explain how /s/ loses its moraic status in singleton onsets.
} 
nuclear [s] when flanked by consonants that must be parsed as onsets (17a); as nucleus+onset [ss] when preceded by an onset and followed by a vowel (17b); as onset+nucleus [ss] when preceded by a vowel (17c.i) or coda (17c.ii) and followed by an onset; and as onset+nucleus+onset [sss] when preceded by a coda and followed by a vowel (17d.ii). ${ }^{9}$ Effectively, then, the consonant preceding or following nuclear [s] can also be realized as $[\mathrm{s}]$, through multiple linking of $/ \mathrm{s}_{\mu} /$, depending on the syllabification requirements of adjacent segments.

\begin{tabular}{|c|c|c|}
\hline Syllabification: & (i) V.Cs.CV & (ii) VC.Cs.CV \\
\hline a. Nuc: & $\begin{array}{l}\text { áa.ko.ks.ta.ki.wa } \\
\text { 'She will count.' (G79) }\end{array}$ & $\begin{array}{l}\text { mí?.ks.ka.pa.yi.nis.tsi } \\
\text { 'crackers' (G65) }\end{array}$ \\
\hline b. Nuc-Ons: & $\begin{array}{l}\text { a.nis.tá.ps.sí.wa } \\
\text { ‘be-3:nonaffirmative' (G133) }\end{array}$ & $\begin{array}{l}\text { ki.ts.so.káP.ps.si } \\
\text { 'You are nice' (G23) }\end{array}$ \\
\hline c. Ons-Nuc: & $\begin{array}{l}\text { í.ss.ka } \\
\text { 'pail' (G14) }\end{array}$ & $\begin{array}{l}\text { o.tsí.ts.so.nao?.ss.ki.po.ka } \\
\text { ‘...then kissed him' (G128) }\end{array}$ \\
\hline d. Ons-Nuc-Ons: & $?$...V.ss.sV ... & $\begin{array}{l}\text { ááh.ss.sa.pi.wa } \\
\text { 'He enjoyed watching' (D258) }\end{array}$ \\
\hline
\end{tabular}

We provide structures for each of the cases in (17) below, beginning with column (i) where the Cs syllable is preceded by a vowel. In $(18 \mathrm{a}), / \mathrm{s}_{\mu} /$ projects a syllable node; the string cannot otherwise be syllabified, as both flanking consonants must be parsed as onsets. Recall from $\S 3$ that $/ \mathrm{k} /$, the consonant preceding $/ \mathrm{s}_{\mu} /$, cannot be syllabified as a coda due to NOCODAPLACE. In (18b), / $\mathrm{s}_{\mu} /$ similarly projects $\sigma$, but the consonant must become an onset as well, yielding [ss]. The alternative parse with short [s] is ruled out due to NoHiatus. In (18c), a vowel precedes $/ \mathrm{s}_{\mu} /$; NoHiATUS thus forces $/ \mathrm{s}_{\mu} /$ to become onset of its own syllable, yielding [ss]. The first alternative parse is ill-formed due to NoCODAPLACE: [s] is only permitted in coda when it can share place with the following onset. The second alternative, where it is the vowel instead of $/ \mathrm{s}_{\mu} /$ that fills the onset position, is ruled out because $/ \mathrm{s} /$ is less sonorous than true vowels: sonority cannot fall toward nucleus. ${ }^{10}$

Syllabification of (i) V.Cs.CV

a. $\quad / s_{\mu} /$ as nucleus: [áa.ko.ks.ta.ki.wa] (17a.i)

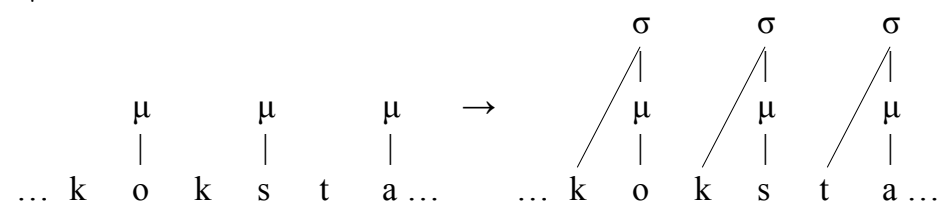

b. $\quad / s_{\mu} /$ as nucleus-onset: [a.nis.tá.ps.sí.wa] (17b.i)

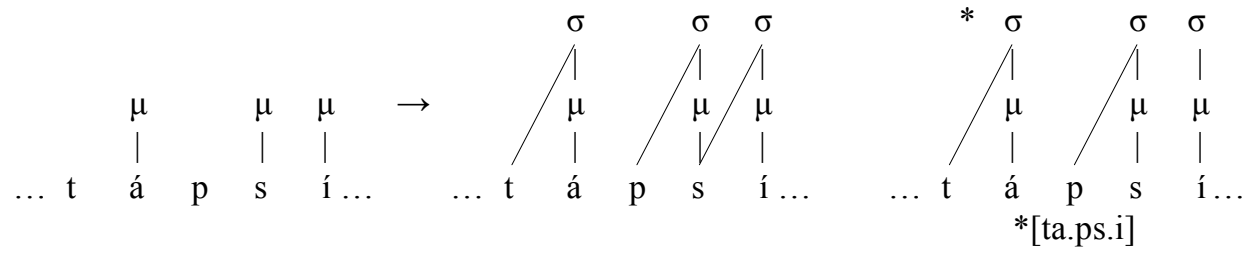

\footnotetext{
${ }^{9}$ We have found no forms of the shape in (17d.i), hence the question mark in this cell. We have no principled reason to exclude forms of this type.

${ }^{10}$ Thanks to Emily Elfner for helpful discussion on the role of sonority here.
} 
c. $\quad / \mathrm{s}_{\mu} /$ as onset-nucleus: [í. $\underline{\text { ss.ka] }}(17 \mathrm{c} . \mathrm{i})$
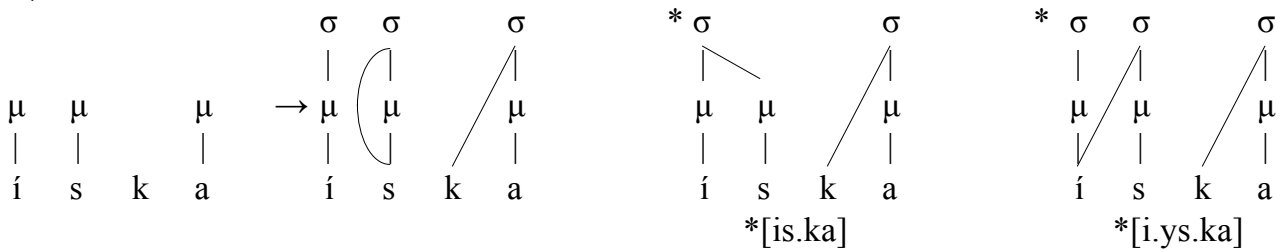

We turn now to column (ii) in (17), where the Cs syllable is preceded by a consonant. The form in (17a.ii), shown in (19a), parallels that in (18a). Since the Cs syllable is preceded by a consonant, however, this syllabification is only possible if the coda+onset cluster is well-formed as per SYLLABLECONTACT and NOCODAPLACE $(\S 3)$. The form in (19b) similarly parallels the structure in $(18 \mathrm{~b})$ : $/ \mathrm{s}_{\mu} /$ heads its own syllable and also becomes the onset of the following syllable, to avoid violating NoHIATUS. The form in (19c) differs somewhat as no onset consonant interrupts glottal stop and $/ \mathrm{s}_{\mu} /$. As $/ \mathrm{R} /$ can only be parsed as a coda to avoid violating ONSETPLACE, $/ \mathrm{s}_{\mu} /$ becomes the onset of its own syllable, in order to satisfy NoHIATUS. ${ }^{11}$ The form in $(19 \mathrm{~d})$ is similar to that in (19c), except that the segment following $/ \mathrm{s}_{\mu} /$ is a vowel. NoHIATUS is thus implicated twice in such a structure, forcing moraic $/ \mathrm{s}_{\mu} /$ to become the onset of its own syllable and the onset of following syllable. ${ }^{12}$

\section{Syllabification of (ii) VC.Cs.CV:}

a. $/ \mathrm{s}_{\mu} /$ as nucleus: [mír.ks..ka.pa.yi.nis.țsi] (17a.ii)

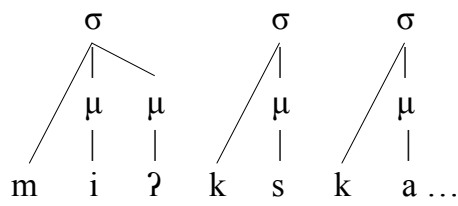

c. $/ \mathrm{s}_{\mu} /$ as onset-nucleus:

[o.tsí.ts.so.nao?.ss.ki.po.ka] (17c.ii)

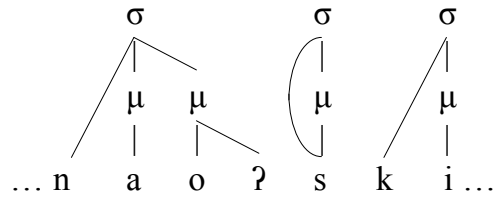

b. $/ \mathrm{s}_{\mu} /$ as nucleus-onset:

[ki.ts.so.ká?.ps.si] (17b.ii)

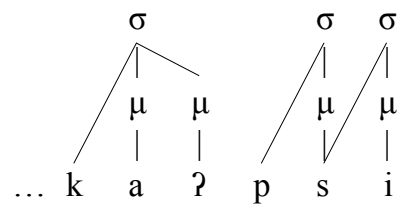

d. $/ \mathrm{s}_{\mu} /$ as onset-nucleus-onset:

/yááhs ${ }_{\mu}$ apiwa/ $\rightarrow$ [áh.ss.sa.pi.wa] (17d.ii)

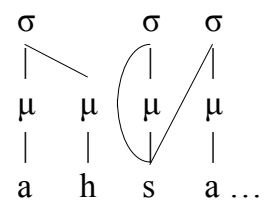

5.3 Bimoraic unusual /s/ Bimoraic unusual /s/ yields Css syllables, as can be seen in (20). As in the table in (17) above, in column (i), the Css syllable is preceded by a vowel and in (ii), by a consonant.

\begin{tabular}{|c|c|c|}
\hline Syllabification: & (i) V.Css.CV & (ii) VC.Css.CV \\
\hline a. Nuc: & $\begin{array}{l}\text { i.tá.pss.ko.na.ki.wai. } \widehat{\text { ksi }} \\
\text { '(My friend) shot at them' (G50) }\end{array}$ & $\begin{array}{l}\text { ik.kss.píí.sa } \\
\text { 'Hit him on the head!' (D45) }\end{array}$ \\
\hline b. Nuc-Ons: & $\begin{array}{l}\text { s.tá.mss.sáa.ko.noo.sa } \\
\text { 'Try to recognize her!' (D166) }\end{array}$ & ?...VP.Css.sV ... \\
\hline c. Ons-Nuc: & $\begin{array}{l}\text { ínikáto?katsiiwa anníisska ó.sss.ka } \\
\text { 'he imitated his son-in-law' (D61) }\end{array}$ & ?...VP.sss.CV ... \\
\hline d. Ons-Nuc-Ons: & * ...V.sss.sV ... & * ...VP.sss.sV ... \\
\hline
\end{tabular}

\footnotetext{
${ }^{11}$ Although $/ \mathrm{a} /+/ \mathrm{o} /$ is normally resolved through fusion $(\S 3)$, Frantz (2009: 161) notes that this sequence of vowels becomes a diphthong before glottal stop. We assume that the three position rhyme, [ao?], is bimoraic, consistent with Hayes (1989).

${ }^{12}$ The initial glide is deleted from this form, as discussed in $\S 3$. In addition, long vowels are shortened before coda $/ \mathrm{h} /$ (Elfner 2006a; see also Frantz 2009).
} 
Structures are provided below for the four types of attested forms in (20). Considering first column (i), $/ \mathrm{s}_{\mu \mu} /$ is syllabified as nuclear [ss] in (21a), as the preceding and following consonant must be onsets, by virtue of their place. Compare the form in (19c), [o.tsí.ts.so.nao?.ss.ki.po.ka], where it is monomoraic/s/ that surfaces as [ss] because the preceding placeless consonant must be a coda. ${ }^{13}$ In (21b), NoHIATUS forces bimoraic /s/ to become onset of following syllable, which would otherwise begin with a vowel. In (21c), this constraint forces $/ \mathrm{s}_{\mu \mu} /$ to become onset of its own syllable because the preceding segment is a vowel.
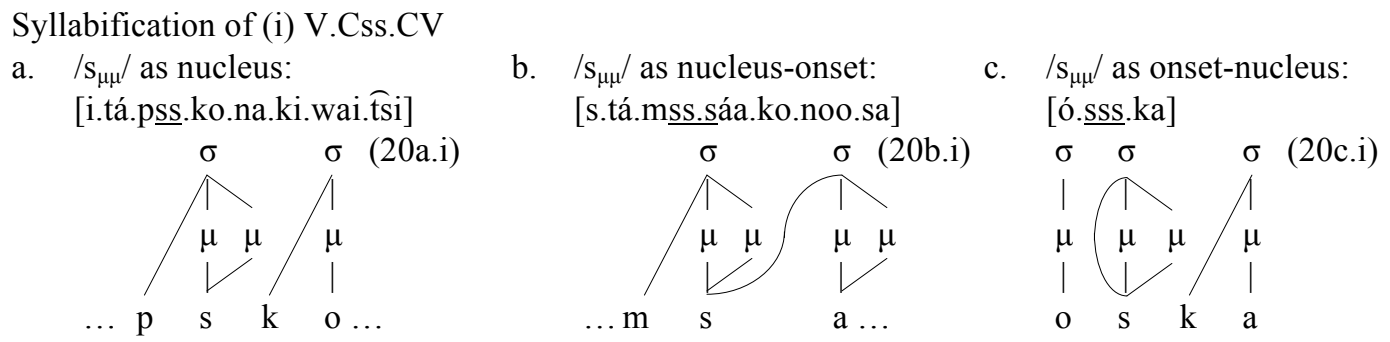

Turning to column (ii), (22) shows that $/ \mathrm{s}_{\mu \mu} /$ is syllabified as nuclear when the Css syllable is preceded by a coda and followed by an onset. ${ }^{14}$

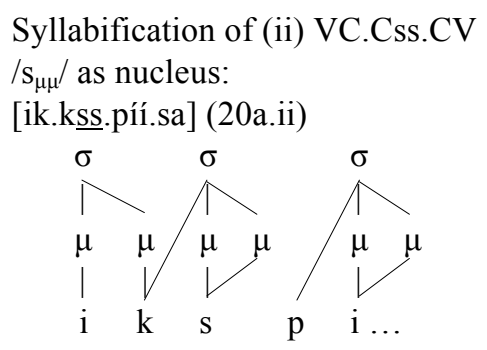

Consider, finally, the onset-nucleus-onset parse for $/ \mathrm{s}_{\mu \mu} /$ in (20d). Note that forms of this shape, both (20d.i) and (20d.ii), are unattested. The maximum surface length for unusual /s/ is [sss], regardless of its syllabification. We expect that the upper limit of [sss] may be driven by phonetic considerations: on articulatory grounds, speakers may have difficulty sustaining the airflow required for the production of an overlong sibilant [ssss]; alternatively, it may prove difficult to perceptually distinguish [sss] from [ssss], which would both occur after laryngeals and before vowels (as in e.g. [áhsssapiwa] in (17d.ii)).

To sum up thus far, our analysis that Blackfoot/s/ is a vocoid can straightforwardly account for a large range of patterns that Blackfoot exhibits in medial position, without relaxing the language's syllable structure constraints on place, sonority and hiatus: the segmental context in which /s/ occurs determines its realization. There are some gaps that we are hopeful will be filled by more careful scrutiny of the wider literature and consultation with native speakers.

\section{Clusters in word-initial position}

In this section, we show how our analysis straightforwardly extends to word-initial /s/ clusters. As discussed above, Blackfoot is similar to other languages where /s/ behaves unusually in that it permits $\mathrm{sC}$

\footnotetext{
${ }^{13}$ All CssC cases are analysed as $/ \mathrm{s}_{\mu \mu} /$ by Denzer-King (2009). This approach does not take into consideration distributional differences observed between place-bearing and placeless consonants (i.e., for the consonant that immediately precedes the sibilant).

${ }^{14}$ We predict forms like ...V?.Css.sV... (20b.ii) and ...VP.sss.CV... (20c.ii) to be well-formed, alongside the attested ...V.Css.sV... (20b.i) and ...V.sss.CV... (20c.i). Although we have found strings of the shape ...VP.Css.sV..., e.g. ami?.tss.so.ki.mi 'Pacific Ocean' (D10), all of them have [t] or [k] in the C position, which likely means that the [tss] or [kss] syllable forms a complex segment in onset $([\mathrm{ts}] /[\mathrm{ks}])+$ singleton nucleus $([\mathrm{s}])$, rather than singleton onset $([\mathrm{t}] /[\mathrm{k}])$ + branching nucleus ([ss]). However, at present, we have no principled reason to rule out forms of the shape ...V?.Css.sV ..., nor those of the shape ...VP.sss.CV....
} 
clusters in initial position (see (23a), repeated from (14a)). Elfner (2006a) analyses such clusters as complex onsets (the same analysis she proposes for medial sC and Cs clusters). Our approach does not permit an analysis of this type, as we do not allow complex onsets of this shape in any language, as mentioned earlier (see further Goad 2011). It is also inconsistent with the observation that Blackfoot does not permit rising-sonority complex onsets.

An alternative would be to treat initial $/ \mathrm{s} / \mathrm{in} \mathrm{sC}$ clusters as an appendix (or extraprosodic), the analysis adopted by Denzer-King (2009). However, recall that Blackfoot also permits ssC, as shown in (23c). A comparison of the datasets in (23a) and (23c) reveals that initial $\mathrm{sC}$ and $\mathrm{ssC}$ are subject to the same constraints: they are both followed by (complex) stops of the same profile, which suggests that the same analysis should hold for both. The problem is that the appendix analysis for initial $/ \mathrm{s} / \mathrm{cannot}$ be extended to Blackfoot ssC, as this would violate the Peripherality Condition: appendix/extraprosodic status can only be assigned to elements in peripheral positions (Hayes 1981, Harris 1983). ${ }^{15}$

The third option is that initial $\mathrm{sC}$ is analysed as a coda+onset cluster, as in Government Phonology (following Kaye 1992). This analysis could extend to initial ssC clusters (\#sØs.CV...), but it is challenged by the observation that medial $\mathrm{sC}$ clusters that are analysed as coda+onset respect place identity while initial sC/ssC clusters do not (compare (23b) with (23a)/(23c)).

a. Word-initial sC:

$$
\begin{array}{ll}
\text { [spátsiko] } & \text { 'sand' (D220, D-K12) } \\
\text { [stámitapo:t] } & \text { 'just go there!' (D232, D-K12) } \\
\text { [stsíki] } & \text { 'another' (D232, D-K12) } \\
\text { [ski:m] } & \text { 'female animal' (D214, D-K12) }
\end{array}
$$

c. Word-initial ssC:

$\begin{array}{ll}\text { [sspitááwa] } & \text { 'He is tall' (G23) } \\ \text { [sstamatsisa] } & \text { 'Tether him to the stake!' (D229) } \\ \text { [sstsipísoohsit] } & \text { 'Punish (whip) yourself!' (G105) } \\ \text { [sskánatsskiniwa] } & \text { 'She has nice hair' (D22) } \\ \text { [ssksó?satsisa] } & \text { 'Flesh a hide!' (D225) }\end{array}$

In view of these considerations, we propose the following analysis for initial $\mathrm{sC}$ and $\mathrm{ssC}$ : [s] is monomoraic and [ss] is bimoraic; see (24). In both cases, /s/ projects a syllable, because the string cannot otherwise be syllabified, as was seen for cases of medial /s/ earlier. ${ }^{16}$

Syllabification:

a. $\quad / \mathrm{s}_{\mathrm{\mu}} /$ for data in $(23 \mathrm{a})$ :

[stsíki]

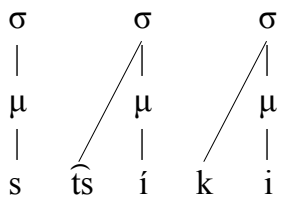

b. $/ \mathrm{s}_{\mu \mu} /$ for data in $(23 \mathrm{c})$ :

[sspákssi?kssaahkoistsi]

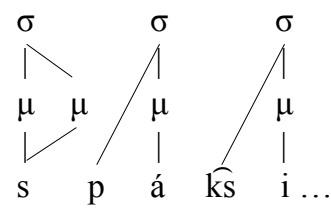

Before concluding, we must ensure that the surface forms in (25) are not accidentally predicted to arise from the representations we have proposed in (24). An 'extra' [s] will not result because there is nothing to drive onset formation in initial position. Onset formation arises under two conditions only: (i) word-initial

\footnotetext{
${ }^{15}$ Although Denzer-King (2009) analyses /s/ in \#sC as a moraic appendix, his analysis for \#ssC is different (he treats [ss] as bimoraic, that is, as a long vowel). As mentioned in the text, we believe that \# $\mathrm{sC}$ and \#ssC should receive a uniform analysis, given that they observe parallel phonotactic constraints.

${ }^{16} \mathrm{SC}$ and ssC are variably preceded by an epenthetic vowel ([ə] or [I] in quality) (Denzer-King 2009; see also Elfner 2006a). We assume that this vowel is weightless, as is the case for epenthetic vowels in some other languages (Piggott 1995), and so links up to the leftmost mora associated with $/ \mathrm{s} /$.
} 
stray consonants undergo onset adjunction; initial /s/ here, however, is not stray; (ii) NoHIATUS is resolved by onset formation; here, there is no hiatus to resolve.

a. $*$ sstsíki $]$

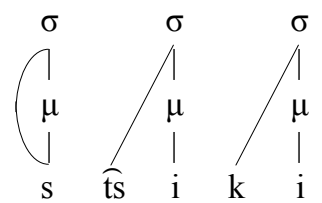

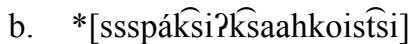

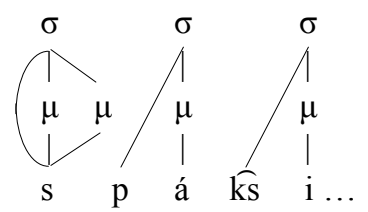

\section{Conclusion}

To sum up, we have argued that Blackfoot /s/ is a vocoid: it can be underlyingly non-moraic, monomoraic or bimoraic. Like other consonants, singleton ordinary $/ \mathrm{s} /$ is underlyingly non-moraic; geminate ordinary /s/ is underlyingly monomoraic. Like vowels, unusual /s/ is underlyingly monomoraic or bimoraic and projects a syllable. Ordinary and unusual /s/ are not formally different, aside fom their moraic content. It is rather the segmental context in which $/ \mathrm{s} /$ occurs that determines its realization and syllabic status; critically, constraints on syllabification (place, sonority, hiatus) must be factored in.

Turning to cross-linguistic implications, it is evident that a unified account of /s/ clusters cannot be provided across languages. However, we contend that it may well be the case that the behaviour of /s/ can always be captured with /s/ being analysed as a conventional syllable constituent (onset, nucleus, coda, moraic), i.e. without requiring recourse to appendices or non-exhaustive syllabification, if one admits a relatively abstract view of the syllable. Specifically, unusual /s/ has been argued to be a coda preceded by an empty nucleus in (initial) sC clusters in Indo-European languages (following Kaye 1992); /s/ has been proposed to be an onset followed by an empty nucleus in initial and medial sC clusters in Acoma (Goad 2011, 2012); and following in the spirit of Denzer-King (2009), /s/ has been proposed here to be moraic and to project its own syllable node in Blackfoot initial and medial clusters. It appears, at present, that the moraic analysis of Blackfoot /s/ cannot be translated into onset rhyme theory, with unusual /s/ analysed as a nucleus. Indeed, moraic theory seems to be the only theory that provides the flexibility required for the various parses of /s/ in Blackfoot.

\section{References}

Clements, G. Nick. 1990. The role of the sonority cycle in core syllabification. In John Kingston and Mary Beckman (eds.), Papers in laboratory phonology I: Between the grammar and physics of speech. Cambridge: CUP, 283333.

Denzer-King, Ryan E. 2009. The distribution of /s/ in Blackfoot: An Optimality Theory account. MA thesis, University of Montana.

Derrick, Donald. 2006. Syllabification and Blackfoot "s". Presented at the $38^{\text {th }}$ Algonquian Conference, UBC, Vancouver, BC, October.

Elfner, Emily. 2005. The role of sonority in Blackfoot phonotactics. Calgary Papers in Linguistics 26: 27-91.

Elfner, Emily. 2006a. The mora in Blackfoot. MA thesis, University of Calgary.

Elfner, Emily. 2006b. Contrastive syllabification in Blackfoot. In Donald Baumer, David Montero \& Michael Scanlon (eds.), Proceedings of the 25th West Coast Conference on Formal Linguistics, 141-149. Somerville, MA: Cascadilla.

Frantz, Donald G. 2009. Blackfoot grammar, $2^{\text {nd }}$ edition. Toronto: University of Toronto Press. ( $1^{\text {st }}$ edition 1991.$)$

Frantz, Donald G. \& Norma Jean Russell. 1995. Blackfoot dictionary of stems, roots and affixes, $2^{\text {nd }}$ edition. Toronto: University of Toronto Press. ( $1^{\text {st }}$ edition 1989.)

Goad, Heather. 2011. The representation of sC clusters. In Marc van Oostendorp, Colin Ewen, Elizabeth Hume \& Keren Rice (eds.), The Blackwell companion to phonology, 898-923. Oxford: Wiley-Blackwell.

Goad, Heather. 2012. sC clusters are (almost always) coda-initial. The Linguistic Review 29: 335-373.

Goad, Heather \& Akiko Shimada. 2014. Syllabification in Blackfoot with an emphasis on /s/. Ms., McGill University.

Hayes, Bruce. 1981. A metrical theory of stress rules. PhD thesis, MIT.

Hayes, Bruce. 1989. Compensatory lengthening in moraic phonology. Linguistic Inquiry 20: 253-306.

Harris, James. 1983. Syllable structure and stress in Spanish. Cambridge, MA: MIT Press. 
Harris, John. 1997. Licensing inheritance: an integrated theory of neutralisation. Phonology 14: 315-370.

Hyman, Larry. 1985. A theory of phonological weight. Dordrecht: Foris.

Itô, Junko. 1986. Syllable theory in prosodic phonology. PhD thesis, University of Massachusetts, Amherst.

Kaye, Jonathan. 1992. Do you believe in magic? The story of $\mathrm{s}+\mathrm{C}$ sequences. SOAS Working Papers in Linguistics 2 : 293-313.

Keating, Patricia. 1988. Underspecification in phonetics. Phonology 5: 275-292.

Murray, Robert W. and Theo Vennemann. 1983. Sound change and syllable structure in Germanic phonology. Language 59: 514-528.

Piggott, Glyne L. 1995. Epenthesis and syllable weight. Natural Language \& Linguistic Theory 13: 283-326.

Qu, Chen. 2011. Prosodic licensing, elaboration of segmental structures and child consonant harmony. In Lisa Armstrong (ed.), Proceedings of 2011 Annual Conference of the Canadian Linguistic Association (CLA-ACL 2011). http://homes.chass.utoronto.ca/ cla-acl/actes2011/Qu 2011.pdf

Rose, Sharon. 1996. Variable laryngeals and vowel lowering. Phonology 13: 73-117.

Steriade, Donca. 1987. Locality conditions and feature geometry. Proceedings of NELS 17: 595-617.

Toda, Martine, Shinji Maeda \& Kiyoshi Honda. 2010. Formant-cavity affiliation in sibilant fricatives. In Susanne Fuchs, Martine Toda \& Marzena Zygis (eds.), Turbulent sounds: An interdisciplinary guide, 343-374. Berlin: Mouton de Gruyter.

Vaux, Bert \& Andrew Wolfe. 2009. The appendix. In Eric Raimy \& Charles Cairns (eds.), Contemporary views on architecture and representations in phonology, 101-143. Cambridge, MA: MIT Press.

Weijer, Jeroen van de. 1996. Segmental structure and complex segments. Tübingen: Max Niemeyer.

Wright, Richard. 2004. A review of perceptual cues and cue robustness. In Bruce Hayes, Robert Kirchner \& Donca Steriade (eds.), Phonetically based phonology, 34-57. Cambridge: CUP. 